\title{
Study of Zr and Sn Doping on Photoluminescence Property of Cadmium Sulphide Nanoparticles
}

\author{
M. Bhagat ${ }^{{ }^{*}}$, P.Lokhande ${ }^{2}$, H.Mujawar ${ }^{3}$ \\ ${ }^{1}$ Research Scholar, ${ }^{2}$ Associate Professor, ${ }^{3}$ Professor, Dr.Babasaheb Ambedkar Technological University, Lonere, India \\ \{madhurisd16@gmail.com\}
}

\begin{abstract}
Semiconductor nanoparticles have drawn significant attention due to their excellent application in optoelectronics and photonics. Cadmium Sulphide extended its application in the field of photoluminescent materials. In present study, $\mathrm{Zr}$ and $\mathrm{Sn}$ doped Cadmium Sulphide nanoparticles prepared by Chemical coprecipitation method. The morphology of nanomaterial was examined with the scanning electron microscopy (SEM). EDX spectra confirmed the presence of $\mathrm{Zr}$ and $\mathrm{Sn}$ in Cadmium Sulphide material. X-ray diffraction analysis explains the range of material synthesized is in nanoscale. Photoluminescence property was studied by PL spectra and it was observed that $\mathrm{Zr}$ and $\mathrm{Sn}$ doped CdS nanomaterial shows excellent photoluminescency stoichiometric proportion synthesis of doped CdS material hamper the intensity.
\end{abstract}

Keywords: Photoluminescence, nanoparticles, coprecipitation method

\section{Introduction}

Photoluminescence is the emission of light by absorbing photons. It is caused by moving of electrons to higher levels by the absorption of photons. In case of solid, the electronic states of solid are excited by some energy from an external source and excited energy is released as a light. Cadmium Sulphide is one of the most important semiconductor because of its physical, chemical, optoelectronics and photoluminescence property. It has a band gap of $2.42 \mathrm{eV}$ which can easily tuned by adding impurities. Cadmium Sulphide when radiated with UV light, it shows green luminescence. Photoluminescent Cadmium Sulphide may have applications in fluorescent lamps, PL-LCD, Plasma display, LASERs, LSCs, Paints[1]. Earlier researchers have doped Cadmium Sulphide with transition metals and rare earth metals that shows grate potential in various applications. Also the photoluminescence intensity of Cadmium Sulphide is tunable by doping it with transition metal and post transition metal.

There are several methods to synthesize Cadmium Sulphide nanoparticles like solgel method, mechanochemical method, surface ionic layer adsorption and reaction method (SILAR), microemulsion method spray pyrolysis method, chemical bath deposition method and chemical coprecipitation method etc. In present work $\mathrm{Zr}$ and $\mathrm{Sn}$ doped Cadmium Sulphide nanoparticles were synthesized by coprecipitation method. It is very efficient, having simple route of synthesis and requires less environmental conditions. It consumes less time for the synthesis.

\section{Experimental Work}

\subsection{Synthesis of Zr and Sn doped CdS}

Cadmium sulphide nanoparticles doped with $\mathrm{Zr}$ and $\mathrm{Sn}$ were prepared by chemical coprecipitation method. For the synthesis of CdS nanaparticles, cadmium acetate dihydrate $(0.01 \mathrm{M})$, zirconyl nitrate $\mathrm{ZrO}\left(\mathrm{NO}_{3}\right)_{2}(0.01 \mathrm{M})$, stannous chloride $\mathrm{SnCl}_{2 .} 2 \mathrm{H}_{2} \mathrm{O}(0.01 \mathrm{M})$, and sodium sulphide were used.. All the chemicals were analytical grade. Distilled water was used as solvent.

For the synthesis $2.66 \mathrm{~g}$ cadmium acetate, $2.25 \mathrm{~g}$ stannous chloride and $2.312 \mathrm{~g}$ of Zirconyl nitrate were dissolved in distilled water separately. Also the $1.14 \mathrm{~g}$ of sodium sulphide was dissolved in distilled water. The mixture of cadmium acetate, stannous chloride and Zirconyl nitrate was stirred on magnetic stirrer.

B. Iyer, S. Nalbalwar and R. Pawade (Eds.)

ICCASP/ICMMD-2016. Advances in Intelligent Systems Research.

Vol. 137, Pp. 54-58.

(C) 2017. The authors - Published by Atlantis Press

This is an open access article under the CC BY-NC license (http://creativecommons.org/licens)es/by-nc/4.0/). 
Sodium sulphide was added drop wise with constant stirring. Ammonia solution was added to maintain the $\mathrm{pH} 11$ [2].Yellowish solution was formed. The mixture was then stirred at $70^{0} \mathrm{C}$ for about one hour. Yellow colournanoparticles were filtered, washed with water and acetone several times to remove the organic residue present in the nano compound. Then sample was taken to the hot air oven for about 6-8 hours then it was kept stored in desiccators before taken to characterization.

\subsection{Characterisation of Sample}

The samples were characterized to determine the morphology of prepared nanomaterial by SEM, elemental analysis to confirm doping of $\mathrm{Zr}$ and Sn by EDX and crystal structure by XRD. The photoluminescence spectra were recorded on Fluorescence spectroscopy. For the analysis of sample on fluorescence spectrometer 1x 10${ }^{5} \mathrm{mM}$ solution was prepared in methanol.

\section{Results and discussion}

\subsection{SEM images}

Figure $\mathrm{a}$ and $\mathrm{b}$ shows the SEM images of $\mathrm{Zr}$ and Sn Doped CdS showing clusters of nanoparticles equally distributed. Most of the particles are spherical in shapes. SEM data reveals particles are nanosized. The surface grain size is more than void area which indicates the formation of high quality crystals.

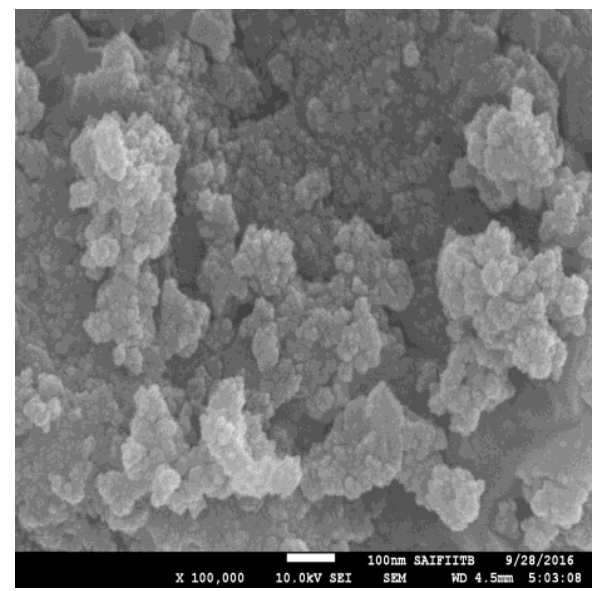

Fig. 1.

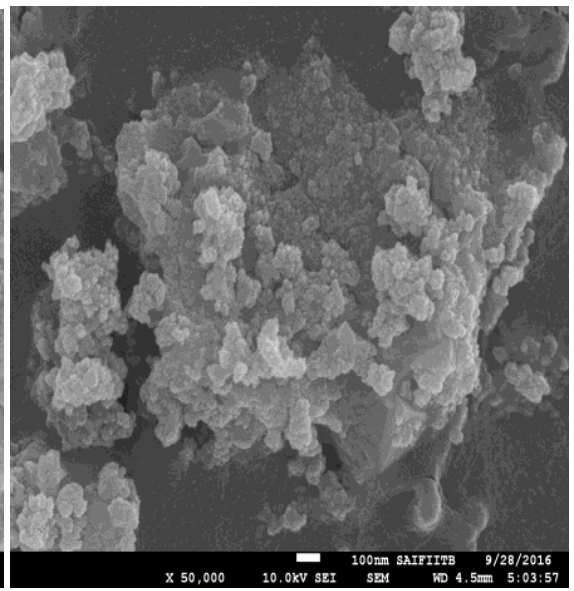

Fig. 2.

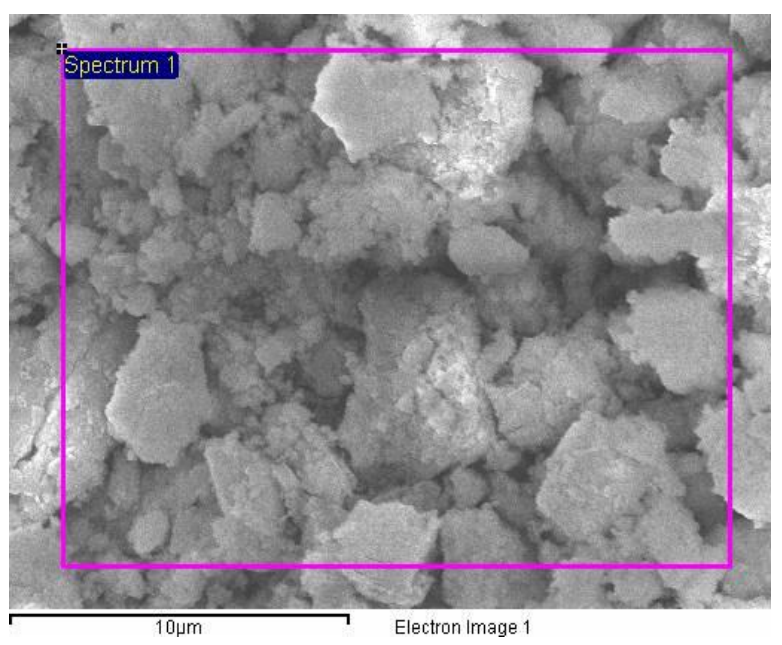

Fig. 3

Fig. 1, 2 and 3. Images of $\mathrm{Zr}$ and Sn Doped CdS 


\section{$3.2 E D X$}

Energy Dispersive X-ray analysis data confirmed the CdS naonparticles doped with $\mathrm{Zr}$ and Sn elements .The EDX results also confirms prepared $\mathrm{Zr}$ and $\mathrm{Sn}$ doped cadmium sulphide having consistent stoichiometric composition.

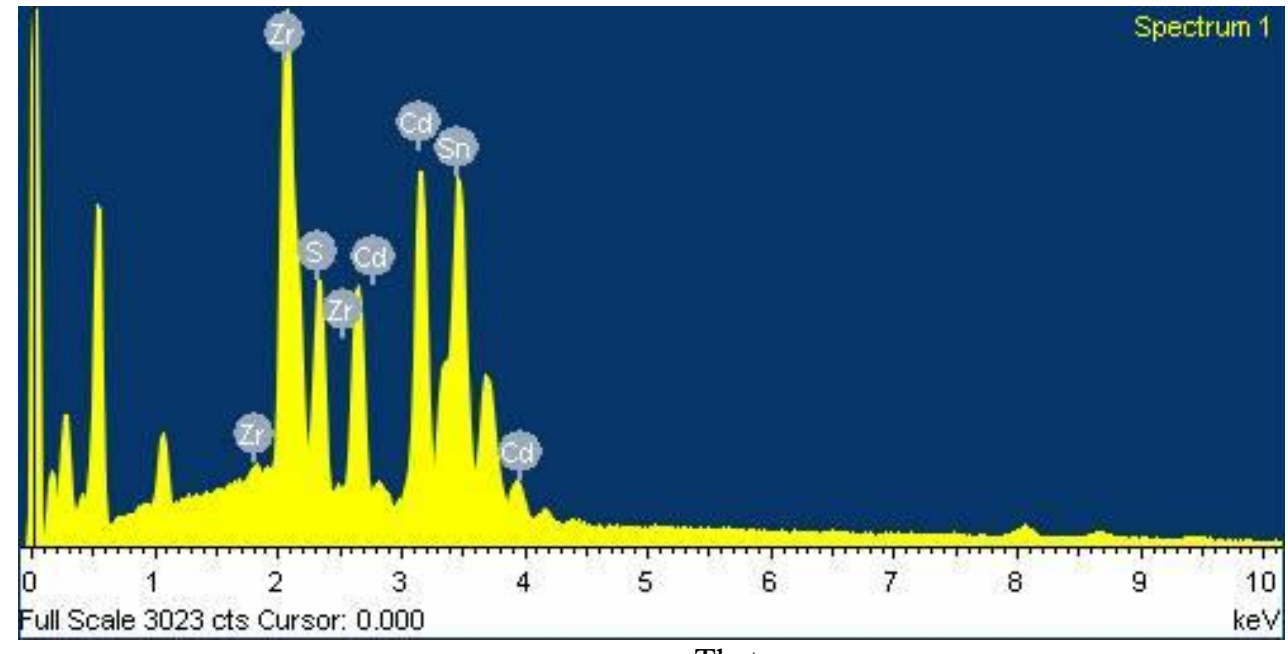

Theta

Fig. 4. EDX image of $\mathrm{Zr}$ and $\mathrm{Sn}$ doped $\mathrm{Cds}$

Table 1 EDX analysis showing composition of the sample

\begin{tabular}{|l|l|l|}
\hline Element & Weight\% & Atomic\% \\
\hline S K & 6.67 & 19.24 \\
\hline Zr L & 28.24 & 28.65 \\
\hline Cd L & 30.97 & 25.50 \\
\hline Sn L & 34.12 & 26.60 \\
\hline Totals & 100.00 & 100.00 \\
\hline
\end{tabular}

\section{$3.3 X R D$}

$\mathrm{X}$ - ray diffraction Study shows the sample prepared is in crystalline form. The diameter of peak confirms nano size particles are having a crystal structure. The particle size of the crystal is $53 \mathrm{~nm}$ calculated by Sherrer Formula.

$$
\begin{gathered}
d=\frac{K \lambda}{\beta \cos \theta} \\
d=\frac{0.9 \times 1.54060}{0.1535 \times 0.1308}
\end{gathered}
$$

Crystal size $\mathrm{d}=53 \mathrm{~nm}$ 


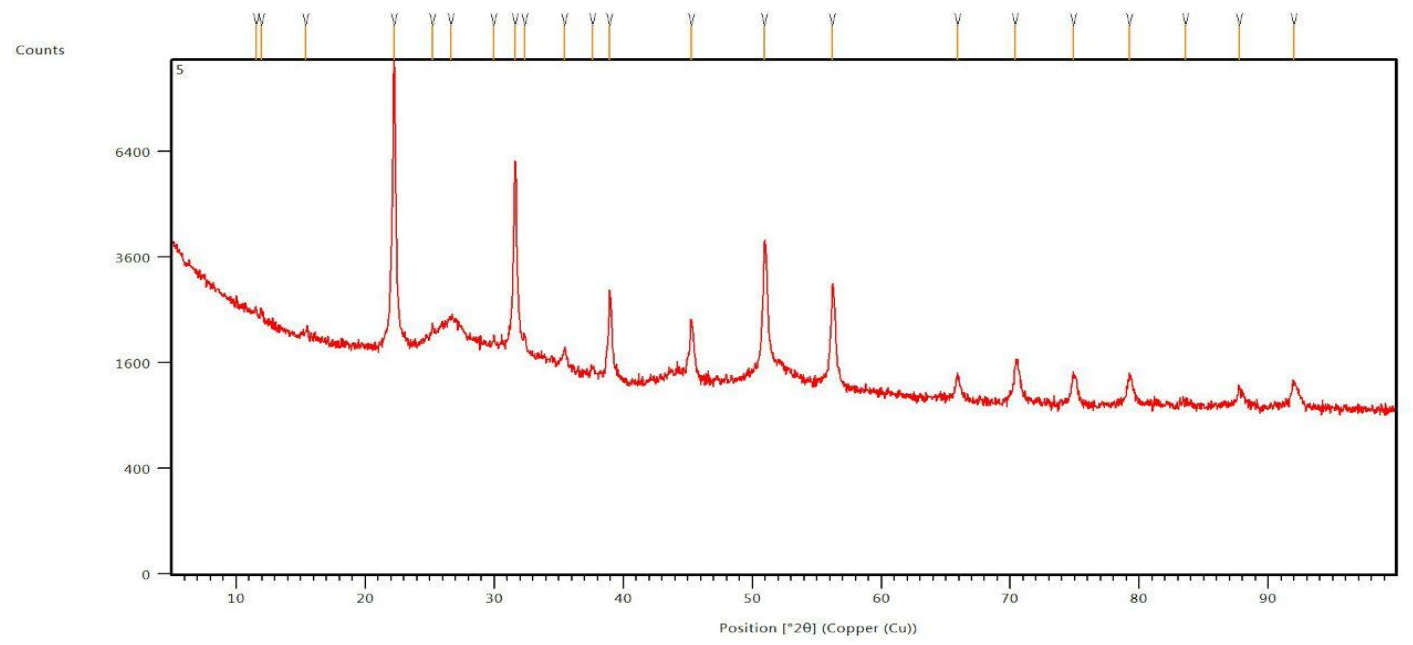

Fig. 5. XRD pattern of $\mathrm{Zr}$ and $\mathrm{Sn}$ doped $\mathrm{CdS}$

\subsection{Photoluminescence spectroscopy}

$\mathrm{Zr}$ and Sn Doped Cadmium Sulphide shows yellow colour and no luminescence and no luminescence in visible light but shows green coloured photoluminescence in UV -light.

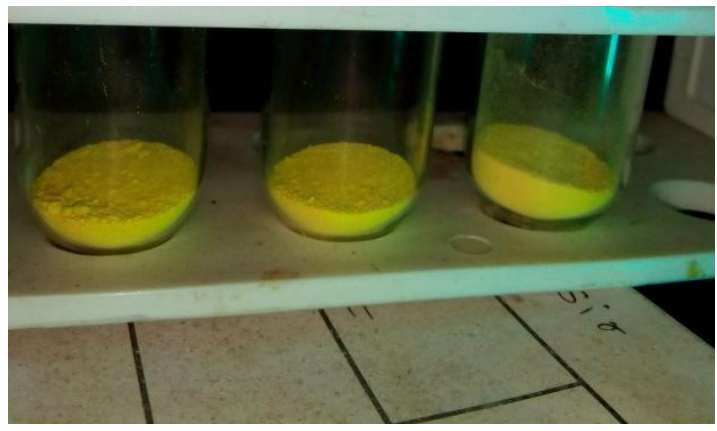

Fig. 6.

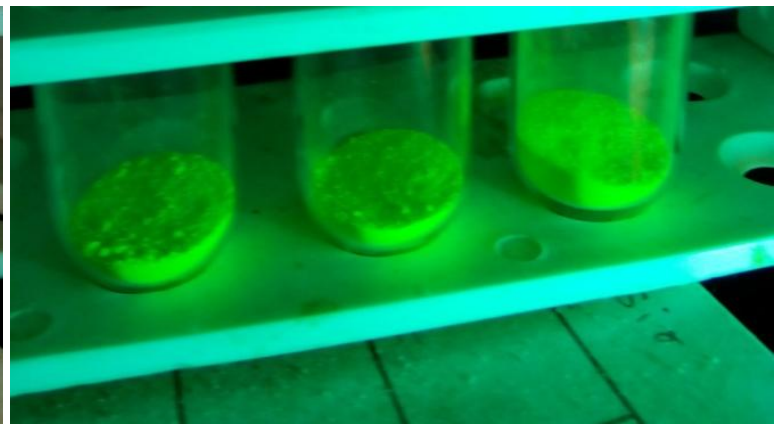

Fig. 7.

Fig. 6 and 7 Visible light and UV light image of $\mathrm{Zr}$ and $\mathrm{Sn}$ doped CdS showing green photoluminescence.

Photoluminescence spectra of $\mathrm{Zr}$ and $\mathrm{Sn}$ doped Cadmium sulphide were recorded on fluoroscence spectrometer ( Instrument RF-5301).

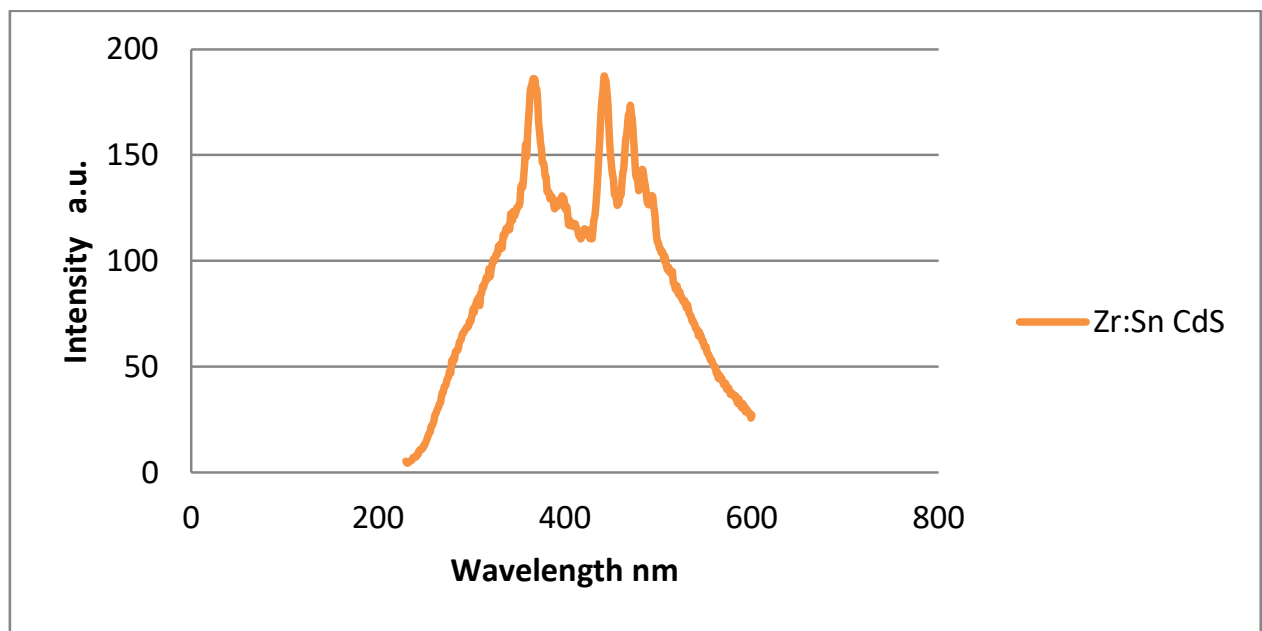

Fig. 8. Photoluminescence spectra of $\mathrm{Zr}$ and $\mathrm{Sn}$ doped $\mathrm{CdS}$ 
The spectra exhibit sharp emission peaks i.e. intensity peaks at $442 \mathrm{~nm}, 443 \mathrm{~nm}$ and $366 \mathrm{~nm}$.It shows the intensity $187.266,185.987$ and 186.062 respectively. It is clear from figure that $\mathrm{Sn}$ and $\mathrm{Zr}$ doped Cadmium sulphide shows the excellent photoluminescence. This means $\mathrm{Zr}$ and $\mathrm{Sn}$ doped $\mathrm{CdS}$ is good phosphor.

\section{Conclusions}

Formation of yellow colored crystals confirmed the formation of doped cadmium Sulphide. Zr and Sn doped Cadmium Sulphide nanomaterial prepared by chemical co-precipitation method is highly crystalline structure. Stannous and zirconium doped Cadmium Sulphide is an excellent photoluminescent semiconductor.

\section{Acknowledgement}

All the experimental work is supported by Department of Chemistry, Dr. Babasaheb Ambedkar Technological University, Lonere, Raigad.

\section{References}

[1]. S.B.Pande, V.R.Raghorte, A.C.Sisyawar, 'Study of luminescnce materials and its scientific application', Bionano Frontier, Vol.5, 2012

[2]. Saravanan L., Jayavel R., Pandurangan A., Liu Jih-Hsin, Miao Hsin-Yuan, Synthesis, 'Structural and optical properties of $\mathrm{Sm}^{3+}$ and $\mathrm{Nd}^{3+}$ doped cadmium sulphide nanocrystals', Materials Research Bulletin 52 (2014) 128-133

[3]. P.Sreekumari. N.Revaprasadu, I. Radhakrishnan, G.A.Kolawole, 'preparation of CdS nanoparticles used in the cadmium (II) comples N, N-BIS (thiocarbamoyl) hydrazine as a simple single source precursor' J.Mater.Chem.II, (2001)1555-1556.

[4]. P.Venkatesu, K.Ravichandran, 'Mangnese doped Cadmium Sulphide (CdS: Mn) Quantum particles : Topological, Photolumunescence and Magnetic Studies', Advance Material Letters, 2013, 4(3), 202208

[5]. Archana Srivastava and H.L.Vishwakarma, 'Photoluminescence of chemically synthesized CdS nanoparticles', International journal of pure and applied physics, volume 6, number 3(2010), pp.347351

[6]. A. I. Iorgu, D.Berder, L. Alexanderscu, B. S. Vasile, C. Matie , 'Synthesis of photoluminescent pure and dopedcadmium Sulphide by reverse microemulsion method', Chalcogenide Letters, Vol. 10.,No. !0,2013,525-531

[7]. Jayapriya J, Gunasekaran M and Seenuvasakumaran P, 'Structural and optical properties of group II-IV Nanofilms by SILAR method', International Journal of Innovative Research and Engineering, ISSN(online)2347-3207 